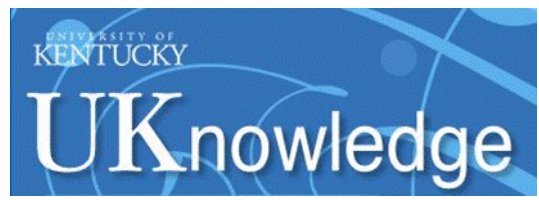

University of Kentucky

UKnowledge

Power and Energy Institute of Kentucky Faculty Publications

Power and Energy Institute of Kentucky

9-2019

\title{
Axial-Field Vernier-Type Flux Modulation Machines for Low-Speed Direct-Drive Applications
}

\author{
Vandana Rallabandi \\ University of Kentucky, vandana.rallabandi@uky.edu \\ Peng Han \\ University of Kentucky, peng.han@uky.edu \\ Murat G. Kesgin \\ University of Kentucky, murat.kesgin@uky.edu \\ Narges Taran \\ University of Kentucky, narges.taran@uky.edu \\ Dan M. Ionel \\ University of Kentucky, dan.ionel@uky.edu
}

Follow this and additional works at: https://uknowledge.uky.edu/peik_facpub

Part of the Power and Energy Commons

Right click to open a feedback form in a new tab to let us know how this document benefits you.

\section{Repository Citation}

Rallabandi, Vandana; Han, Peng; Kesgin, Murat G.; Taran, Narges; and Ionel, Dan M., "Axial-Field VernierType Flux Modulation Machines for Low-Speed Direct-Drive Applications" (2019). Power and Energy Institute of Kentucky Faculty Publications. 15.

https://uknowledge.uky.edu/peik_facpub/15

This Conference Proceeding is brought to you for free and open access by the Power and Energy Institute of Kentucky at UKnowledge. It has been accepted for inclusion in Power and Energy Institute of Kentucky Faculty Publications by an authorized administrator of UKnowledge. For more information, please contact UKnowledge@lsv.uky.edu. 


\title{
Axial-Field Vernier-Type Flux Modulation Machines for Low-Speed Direct-Drive Applications
}

\author{
Digital Object Identifier (DOI)
}

https://doi.org/10.1109/ECCE.2019.8912550

\section{Notes/Citation Information}

Published in 2019 IEEE Energy Conversion Congress and Exposition (ECCE).

(C) 2019 IEEE Copyright Notice. "Personal use of this material is permitted. Permission from IEEE must be obtained for all other uses, in any current or future media, including reprinting/republishing this material for advertising or promotional purposes, creating new collective works, for resale or redistribution to servers or lists, or reuse of any copyrighted component of this work in other works."

The document available for download is the authors' manuscript version that is accepted for publication. The final published version is copyrighted by IEEE and available as: V. Rallabandi, P. Han, M. G. Kesgin, N. Taran, and D. M. Ionel, "Axial-field Vernier-type Flux Modulation Machines for Low-speed Direct-drive Applications," 2019 IEEE Energy Conversion Congress and Exposition (ECCE), Baltimore, MD, Sept. 29-Oct. 3, 2019, pp. 3123-3128, doi: 10.1109/ECCE.2019.891255 


\title{
Axial-field Vernier-type Flux Modulation Machines for Low-speed Direct-drive Applications
}

\author{
Vandana Rallabandi*, Peng Han, Murat Gurhan Kesgin, Narges Taran, and Dan M. Ionel \\ SPARK Laboratory, ECE Dept, University of Kentucky, Lexington, KY, USA
}

vandana.rallabandi@ieee.org, peng.han@uky.edu, murat.kesgin@uky.edu,narges.taran@uky.edu, dan.ionel@ieee.org

\begin{abstract}
This paper proposes different configurations of axial-field machines featuring a very large ratio of the number of rotor poles to stator teeth and coils suitable for low-speed direct-drive traction applications. The machines have a single rotor with spoke-type permanent magnets and the stator teeth include auxiliary slots, the function of which is to enhance the high-polarity component of the stator magnetomotive force interacting with the rotor to produce a net torque. The machines can be constructed with three or two phases, in which case they inherently exhibit high tolerance to faults due to the combined effect of a lack of coupling between phases and a relatively large phase inductance. A preliminary comparative simulation study shows performance improvement over a conventional reference permanent magnet synchronous machine.

Index Terms-Axial-field, direct-drive, flux concentration, flux modulation, fault tolerance, permanent magnet synchronous machine, low-speed
\end{abstract}

\section{INTRODUCTION}

In-wheel motors are being increasingly sought in automotive applications in an attempt to simplify the drive train and eliminate gear boxes, which constitute points of failure. In this regard, high-polarity permanent magnet (PM) synchronous machines with fractional-slot concentrated windings, which feature high efficiency, torque density and power factor are commonly employed. Other competitive candidates include the vernier-type, conceptualized first in [1], followed by others, notably [2], [3].

High-polarity PM machines in low-speed applications lead to increased torque density and efficiency, due to the reduction in the flux per pole linked by the stator winding, which allows the use of more compact magnetic parts, as well as shorter end turn volume. Larger rotor polarities require a proportional increase in the number of stator slots and coils, which, for a specified envelope, may become too small to be practically manufacturable. For example, the slot width may become comparable to the thickness of coil insulation, leading to very poor slot filling, increased winding resistance and conductor losses. To address such limitations, a three-phase radial-field vernier-type PM machine with 46 rotor poles, and only 6 stator coils has been proposed in [4]. Other recent papers on the subject with radial- and axial-field versions include [5], [6]. In addition, a three-phase axial-field version with a

\footnotetext{
* Dr. Vandana Rallabandi was with the SPARK Laboratory, ECE Department, University of Kentucky, Lexington, KY and is now with GE Research, Niskayuna, NY.
}

central yokeless stator and two high-polarity spoke rotors was proposed by the authors in [7].

This paper presents a two-phase machine topology, which also features a large disparity between the number of stator coils and rotor poles, such that, for example, as few as four stator winding coils can be used with as many as sixty rotor poles. Compared with three-phase topologies, the proposed two-phase machines can achieve a higher polarity for a given number of stator slots and coils. More specifically, this paper presents a two-phase axial-field vernier-type flux modulation (VTFM) PM machine with two stators and a high-polarity central spoke rotor. The stators include teeth with slots and notches and concentrated coils. The second stator can also be constructed without coils. The advantages of a two-phase construction include the inherent absence of mutual coupling between phases, which promotes the fault-tolerant capability desired in direct-drive traction applications.

This paper is organized as follows. Section II introduces the operating principle of the proposed VTFM PM machine, based on which feasible pole-slot combinations are derived. Section III presents the performance characteristics of the VTFM machine based on the finite element analysis (FEA) results for a 16-slot 56-pole example machine. The steadystate performance in both the healthy and faulty conditions is included. A comparison study between the example VTFM machine and a conventional axial-field PM machine is conducted in Section IV. Section V concludes the paper and discusses the futher work.

\section{AnAlysis OF THE OPERATING PRINCIPLE AND TOPOLOGY}

A representative two-phase machine with 44 rotor poles and 8 main stator teeth, each with 3 auxiliary teeth, is illustrated in Fig. 1a. The two stators are circumferentially shifted from each other by one rotor pole pitch, which serves to improve the flux concentration and reduce the flux leakage [8]. A radialfield vernier type PM machine with distributed windings, a central spoke rotor, and two stators shifted from each other by a pole pitch is also proposed in [9]. In another implementation, windings can be eliminated from one of the stators, and since it has no coils, it may be directly integrated with the supporting frame, as shown in Fig. 1b. Such a configuration would be of special interest when the envelope is axially limited, which is usually the case in direct-drive applications. Two 


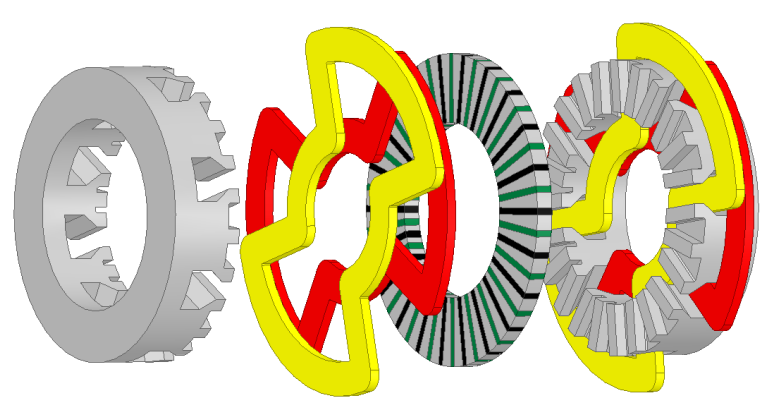

(a)

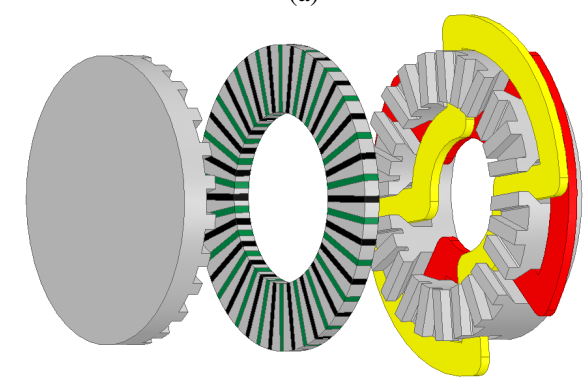

(b)

Figure 1. Three-dimensional views for the proposed VTFM PM machines with 1 central spoke rotor and: (a) two active stators, (b) one active stator and one passive stator. The windings, shown as the wave type, can also be implemented as concentrated, full-pitched or gramme windings.

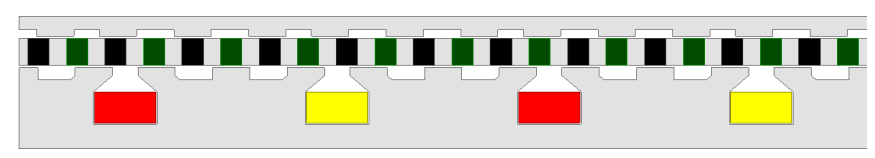

(a)

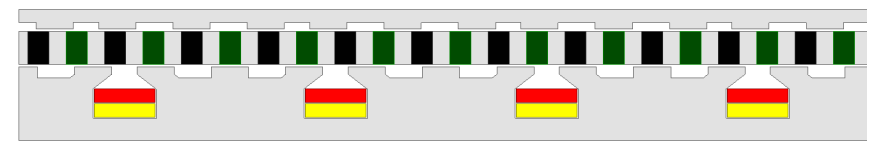

(b)

Figure 2. "Developed" two-dimensional views for the proposed VTFM PM machines with 1-central spoke rotor and a single active stator with: (a) fullpitched winding, (b) concentrated tooth winding. Only half the $2 \mathrm{D}$ view is shown for each winding type.

typical winding types, i.e., the full-pitched winding and the concentrated tooth winding, can be used, as illustrated in Fig. 2 .

The operating principle for these machines is the same as that of other vernier-type PM synchronous motors. The stator coils produce an airgap magnetomotive force (MMF) and armature reaction flux density rich in harmonics, with the magnitude decreasing with the order, in line with expectations. The stator teeth include dummy slots, the function of which is to enhance the stator winding MMF component corresponding to the number of rotor poles. The dummy slots make it possible to use a stator with a relatively small number of teeth and armature coils along with a high polarity rotor.

The number of spoke rotor poles required may be obtained by considering the following two constraints: (a) at a given time, an odd number of PM poles are opposite to each stator tooth, and (b) the required phase shift is achieved between the phases. The first of these conditions ensures that, at a given time, either only north or only south PM poles lead to phase flux linkage. These conditions are mathematically stated as the following for a two-phase machine,

$$
P_{r}>\left(2 t_{a}-1\right) T_{m}, P_{r}=\frac{T_{m}}{2} k_{1},
$$

where $P_{r}$ is the number of rotor poles; $T_{m}$, the number of main stator teeth; $t_{a}$, the number of auxiliary stator slots; and $k_{1}$ is any odd number. For a two-phase machine with 8 main stator teeth, 2 auxiliary or dummy slots, the first value of $P_{r}$ satisfying both these conditions is 28. Additionally, the machines can also be constructed with different winding configurations, with full-pitched coils or concentrated tooth winding (Fig. 2). Some example slot-pole combinations are given (Table I).

Machines of the vernier-type inherently incorporate torque magnification. In AFPM machines, the peak PM flux linkage per phase $\left(\psi_{P M}\right)$ may be approximately given as,

$$
\psi_{P M}=N_{c} B_{g} L_{a} k \frac{\pi D_{m}}{P_{r}},
$$

where $N_{c}$ is the number of coils per phase; $B_{g}$, the air-gap flux density; $L_{a}$, the active length; $k$, a constant; and $D_{m}$, the air-gap diameter. The electromagnetic torque in a motor with $m$ phases with a pure q-axis excitation equal to $I_{q}$ is given as,

$$
T_{e m}=m \frac{P_{r}}{4} \psi_{P M} I_{q}
$$

From (2) and (3), it may be noticed as PM flux linkage reduces with increasing number of rotor poles, the electromagnetic torque is independent of it. Second order effects such as reduction in the stator core volume with the increasing number of poles, and consequently increased slot area, permitting higher values of $I_{q}$ may lead to higher torque.

In the vernier-type PM machines under study in this paper, the number of permanent magnets contributing to the flux linkage of one coil increases linearly with the number of auxiliary slots per main tooth [7]. As observed in Table I, a higher number of rotor poles is required when the number of auxiliary stator slots increases, and therefore, the flux linkage in these types of PM machines is expected to increase with the number of rotor poles. This indicates that these machines would benefit more substantially with higher rotor polarity than conventional machines. Further improvements will also be achieved due to the higher flux concentration in spoke rotors with the increasing number of poles.

The operating principle of these axial-field machines can also be explained by the simple MMF-permeance model. Assuming that there are only fundamental components in the MMF of the spoke rotor and the airgap permeance, the MMF distribution produced by the PM array $f_{m}(\underline{\phi}, t)$ and the airgap permeance $\lambda(r, \phi)$, based on the coordinate system illustrated in Fig. 3 can be written as:

$$
f_{m}(\underline{\phi}, t)=F_{m} \cos \left[p_{m}\left(\underline{\phi}-\phi_{0 m}\right)\right]
$$


Table I

EXAMPLE FEASIBLE MAIN- AND AUXILIARY-SLOT AND ROTOR POLE COMBINATIONS FOR TWO- AND THREE-PHASE MACHINES WITH DIFFERENT TYPES OF WINDINGS. INTEGRAL MULTIPLES OF THESE COMBINATIONS CAN ALSO BE USED.

\begin{tabular}{|c|c|c|c|c|c|c|c|c|c|c|c|c|c|c|c|}
\hline Topology & \multicolumn{3}{|c|}{ Three-phase } & \multicolumn{3}{|c|}{ Three-phase } & \multicolumn{3}{|c|}{ Three-phase } & \multicolumn{3}{|c|}{ Two-phase } & \multicolumn{3}{|c|}{ Two-phase } \\
\hline Main slots & \multicolumn{3}{|c|}{6} & \multicolumn{3}{|c|}{9} & \multicolumn{3}{|c|}{6} & \multicolumn{3}{|c|}{8} & \multicolumn{3}{|c|}{12} \\
\hline Armature poles & \multicolumn{3}{|c|}{4} & \multicolumn{3}{|c|}{6} & \multicolumn{3}{|c|}{2} & \multicolumn{3}{|c|}{4} & \multicolumn{3}{|c|}{6} \\
\hline Winding type & \multicolumn{3}{|c|}{ Conc. } & \multicolumn{3}{|c|}{ Conc. } & \multicolumn{3}{|c|}{ Full } & \multicolumn{3}{|c|}{ Full; Conc. } & \multicolumn{3}{|c|}{ Full; Conc. } \\
\hline Auxiliary teeth & 2 & 3 & 4 & 2 & 3 & 4 & 2 & 3 & 4 & 2 & 3 & 4 & 2 & 3 & 4 \\
\hline Rotor poles & 20 & 32 & 44 & 30 & 48 & 66 & 22 & 34 & 46 & 28 & 44 & & 42 & 66 & 90 \\
\hline Fund. winding factor & \multicolumn{3}{|c|}{0.866} & \multicolumn{3}{|c|}{0.866} & \multicolumn{3}{|c|}{1.000} & \multicolumn{3}{|c|}{$1.000 ; 0.707$} & \multicolumn{3}{|c|}{$1.000 ; 0.707$} \\
\hline
\end{tabular}

$$
\lambda(r, \phi)=\lambda_{0}(r)-\lambda_{1}(r) \cos \left[N_{S P}\left(\phi_{0}-\phi_{0 S P}\right)\right]
$$

where $\phi$ is the angular position in rotor reference frame; $F_{m}$, the amplitude of per-pole MMF created by the PM array; $p_{m}=P_{r} / 2$, the number of rotor pole pairs; $\phi_{0 m}$, the position of the reference axis in rotor reference frame; $\phi$, the angular position in stator reference frame; $N_{S P}=T_{m} t_{a}$, the total number of auxiliary stator slots. $\phi_{0 S P}$ is the position of the reference axis in stator reference frame. $\lambda_{0}$ and $\lambda_{1}$ are the average airgap permeance and the amplitude of the pulsating component, respectively.

The angular positions in rotor and stator reference frames are related to each other by:

$$
\phi=\underline{\phi}+\theta_{r}=\underline{\phi}+\omega_{r} t+\theta_{r 0}
$$

where $\theta_{r}$ is the angle that the rotor rotates relative to the stator, $\omega_{r}$ the rotor speed and $\theta_{r 0}$ the initial position of rotor with reference to the stator. Similarly, all the harmonic components in the stator MMF produced by the stator winding are also neglected for simplicity. The airgap flux density distribution contributed by both the rotor and the stator MMFs is:

$$
\begin{aligned}
& {\left[f_{m}(\phi, t)+f_{s}(\phi, t)\right] \lambda(r, \phi) } \\
= & F_{m} \lambda_{0}(r) \cos \left[p_{m} \phi-p_{m} \omega_{r} t-p_{m}\left(\theta_{r 0}+\phi_{0 m}\right)\right] \\
& +\frac{1}{2} F_{m} \lambda_{1}(r) \cos \left[\left(-p_{m}+N_{S P}\right) \phi+p_{m} \omega_{r} t\right. \\
& \left.-\gamma+\left(\varphi_{s}-p_{s} \phi_{0 s}\right)\right] \\
& +\frac{1}{2} F_{m} \lambda_{1}(r) \cos \left[\left(p_{m}+N_{S P}\right) \phi-p_{m} \omega_{r} t\right. \\
& \left.-\gamma+\left(\varphi_{s}-p_{s} \phi_{0 s}\right)-2 p_{m}\left(\theta_{r 0}+\phi_{0 m}\right)\right] \\
& +F_{s} \lambda_{0}(r) \cos \left[p_{s} \phi+\omega_{s} t+\left(\varphi_{s}-p_{s} \phi_{0 s}\right)\right] \\
& +\frac{1}{2} F_{s} \lambda_{1}(r) \cos \left[\left(-p_{s}+N_{S P}\right) \phi-\omega_{s} t\right. \\
& \left.-\gamma-p_{m}\left(\theta_{r 0}+\phi_{0 m}\right)\right] \\
& +\frac{1}{2} F_{s} \lambda_{1}(r) \cos \left[\left(p_{s}+N_{S P}\right) \phi+\omega_{s} t\right. \\
& \left.-\gamma+2\left(\varphi_{s}-p_{s} \phi_{0 s}\right)-p_{m}\left(\theta_{r 0}+\phi_{0 m}\right)\right]
\end{aligned}
$$

where $F_{s}=\frac{4}{\pi}\left[N_{p h} k_{w 1} I_{s} /\left(2 p_{s}\right)\right] . N_{p h}$ is turns in series per phase, $k_{w 1}$ the fundamental winding factor, $I_{s}$ the amplitude of phase current, $p_{s}$ the number of stator winding pole pairs, and $\phi_{0 s}$ the angular position of phase-A winding axis in stator reference frame.

Equation (7) indicates that, both the rotor MMF and stator

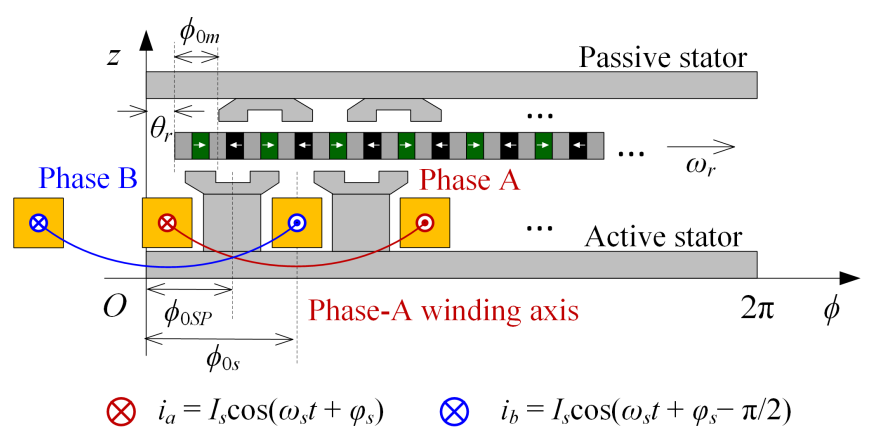

Figure 3. The coordinate system used for theoretical analysis. The proposed VTFM machine with 1-active and 1-passive stator is modeled. It may be noted that the phase sequence is opposite to the rotating direction of the spoke rotor, which is different from conventional PM machines.

MMF have additional magnetic field components due to the presence of the auxiliary stator slots. The rotor MMF has components corresponding to different number of pole pairs, i.e., $p_{m}$ and $N_{S P} \pm p_{m}$, and rotating at different speeds. The pole pairs of those airgap magnetic field components associated with the stator MMF are $p_{s}$ and $N_{S P} \pm p_{s}$, respectively. Nonzero electromagnetic torque will be produced once one or more airgap field components due to the stator MMF synchronize with other components produced by the rotor MMF. It may be noted that the slot pole combinations of Table I can also be derived by considering the rotor and stator MMFs to be synchronous as per the following,

$$
p_{m}=N_{S P}-p_{s}
$$

Manufacturing challenges can arise in these machines owing to the slotted and notched stator teeth. A more feasible approach may be to construct the machine similar to other axial-field PM machines, and add a modulating layer with slots and teeth afterward. The modulating layer can be made of soft magnetic composite material, and affixed to the stator structure through a dovetail.

\section{Modeling of The VTFM PM Machine}

In order to study the performance of the proposed machine configurations, an example two-phase 16-slot 56-pole example machine, as illustrated in Fig. 4 is modeled via 3-dimensional (3D) FEA. Although the machine can be configured with as few as four stator slots and coils, a 16-slot example is chosen 


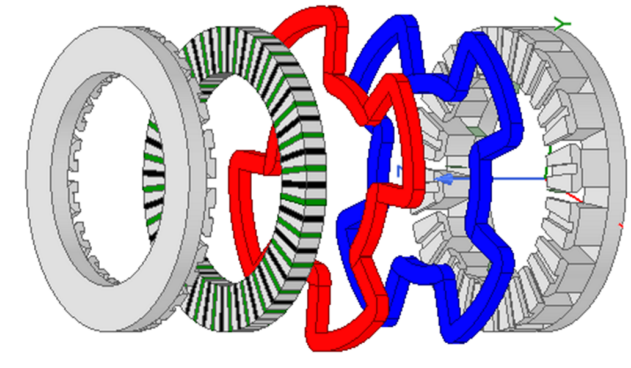

Figure 4. Exploded view for the VTFM example machine with 16 stator slots and 56 rotor poles. In an alternate implementation, a modulating structure comprising discrete soft magnetic poles can be placed between the rotor and each stator. In this case, the stator can be made by conventional stamping techniques, thereby greatly simplifying the manufacturing.

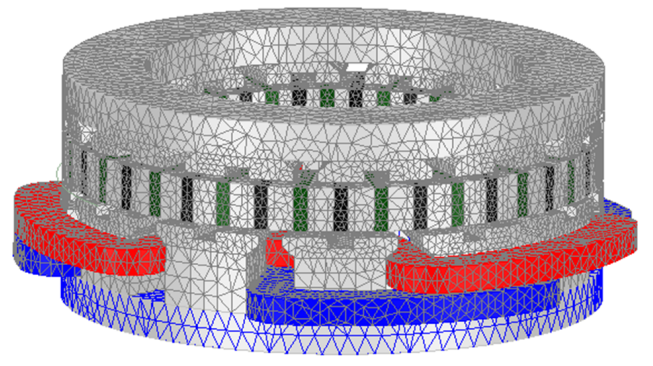

Figure 5. Mesh plot used in the 3D FEA model for the VTFM example machine with 16 stator slots and 56 rotor poles. The full problem featured 239193 tetrahedral elements and a quarter model is analyzed to reduce the computational burden.

for illustration due to the shorter end turns. The full 3D model, along with the mesh employed in the computational study is shown (Fig. 5). The computed back-EMF at the rated speed of 600rpm shows little THD (Fig. 6a). The torque waveforms for a full electrical cycle at half-load and full-load conditions are presented (Fig. 6b). Low torque ripple $(<10 \%)$ is observed even at full-load.

The torque of the 16-slot 56-pole VTFM machine versus the current angle is calculated with 3D FEA and illustrated in Fig. 7a and Fig. 7b for half-load and full-load conditions, respectively. It can be seen that with the increase of the stator current, the current angle where the peak torque occurs deviates slightly from the theoretical value of 90 degrees. This indicates that the VTFM PM machine shows weak magnetic saliency when the laminated core is saturated.

Based on the phasor diagram for steady state operation, it can be shown that the power factor angle $\varphi$ depends on current angle $\gamma$, PM flux linkage $\left|\psi_{P M}\right|$ and stator winding inductance $L_{s}$ as given by the following:

$$
\frac{L_{s} I_{s}}{\left|\psi_{P M}\right|}=\frac{-\cos (\gamma+\varphi)}{\cos \varphi}
$$

If $i_{d}=0$ control is used, $\gamma$ is $\pi / 2$, and (9) can be simplified to:

$$
\cos \varphi=\frac{1}{\sqrt{1+\left(L_{s} I_{s} / \psi_{P M}\right)^{2}}}
$$

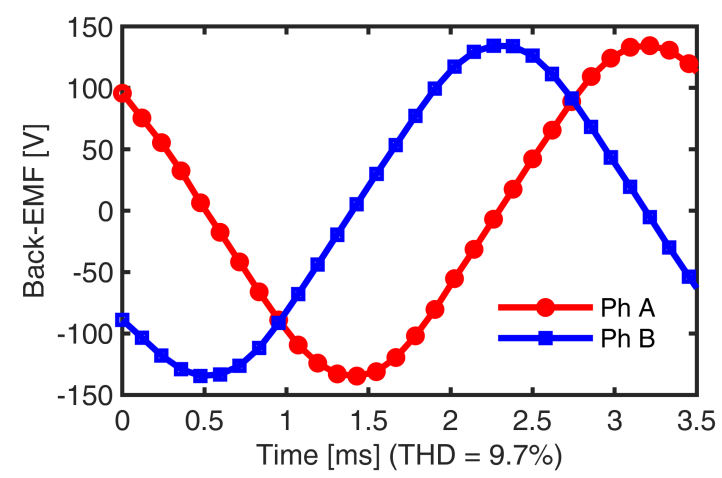

(a)

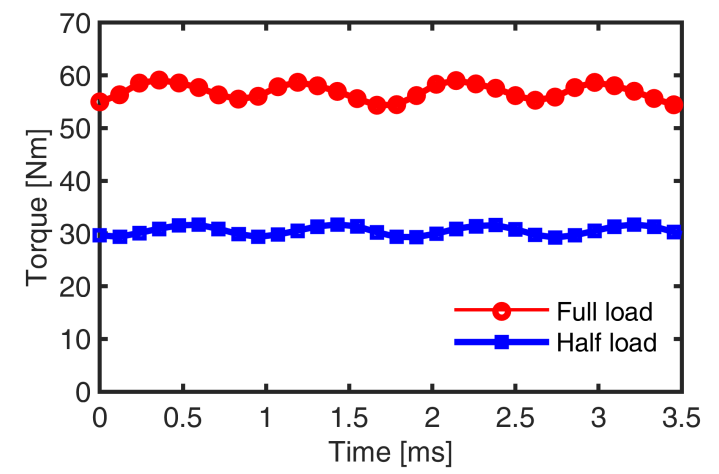

(b)

Figure 6. Three dimensional FEA results for the 16-slot 56-pole example machine: (a) open-circuit back-EMF, (b) torque with a pure q-axis current excitation. The back-EMF has low THD and the torque ripple is within $10 \%$ for both the half-load and full-load conditions.

Equation (9) indicates that the power factor is also impacted by the loading level, i.e., $I_{s}$, and the current angle $\gamma$. Higher power factors are more likely to be achieved in the case of machines with smaller electric loadings, for example, naturally cooled machines (Fig. 7).

\section{Peformance Comparison with Conventional AXIAL-FIELD PM MACHINES}

The performance of the VTFM PM machine is compared with that of a standard three-phase surface-mounted PM synchronous machine designed for solar car application [10] (Fig. 8). This baseline conventional machine has 36 stator slots and 12 rotor poles, featuring a single-stator single-rotor construction with distributed windings. The dimensions and specifications of the machines are summarized (Table II).

The performance comparison between the vernier-type machine and the baseline conventional axial-field PM machine is also tabulated in Table II. The airgap length of the baseline machine is modified on the fly to achieve field weakening and the torques at various airgap lengths computed by 3D FEA are shown (Fig. 9). In order to enable a basic comparison of electromagnetic performance, the baseline machine was simulated with an airgap length of $2.5 \mathrm{~mm}$. More elaborate systematic studies are beyond the space constraints and scope of this paper. 


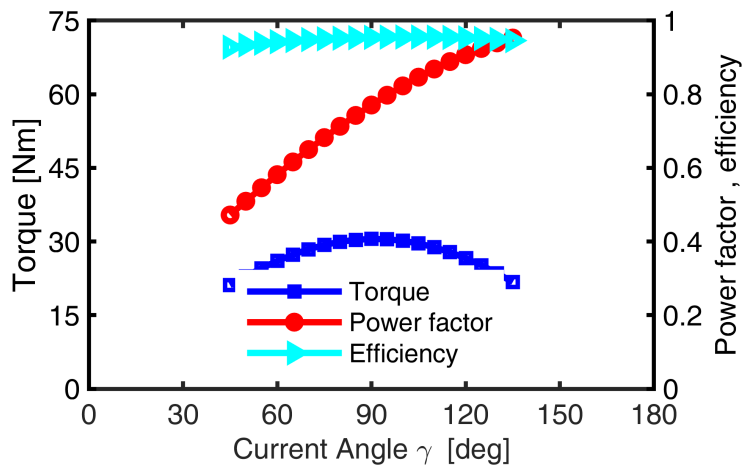

(a)

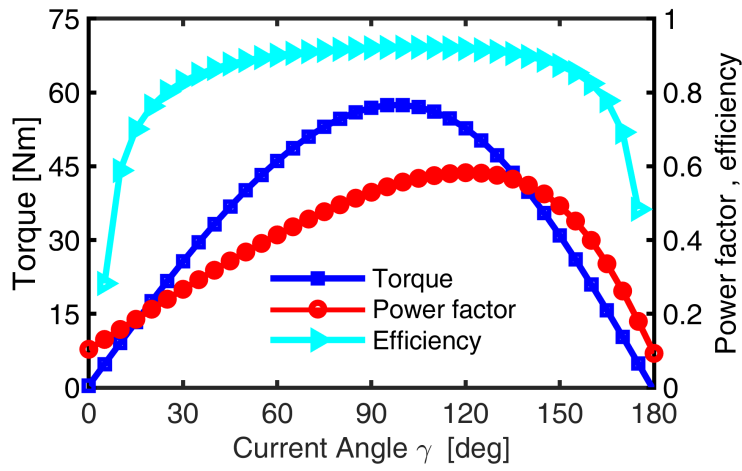

(b)

Figure 7. Three-dimensional FEA-predicted torque, power factor and efficiency at different current angles, (a) half-load condition, (b) full-load condition. Maximum torque per ampere is achieved at approximately 90 degrees, which indicates that the VTFM machine has very little saliency.

It can be observed that, in line with expectations from the qualitative explanations in the previous sections, the proposed machine can be designed with lower copper loss than the conventional machine. However, its core losses are substantially higher. This may be attributed to the multi-harmonic feature of the VTFM machines, and the greatly increased operating frequency for the same speed. This indicates that these machines are more suited for low-speed direct-drive type applications. The power factor is also lower than in the conventional machine, which emphasizes that the application for this type of machine is in the direct-drive applications, in which typically, the machine is substantially more expensive that the converter due to the large size.

It may be noted that a difference between the results from $3 \mathrm{D}$ and 2D FEA is observed, indicating that the 2D analysis performed at the mean diameter is not accurate enough for the analysis of this type of machine. This may be attributed to the significant saturation at the inner diameter. Optimization studies for this machine would therefore require 3D FEA.

\section{Steady-state Operation in the Faulty Mode}

Owing to the two-phase construction, the proposed verniertype machines feature an inherent lack of mutual coupling between two phases. This is verified by FEA results, as shown in Fig. 10a and Fig. 10b. In order to reduce the

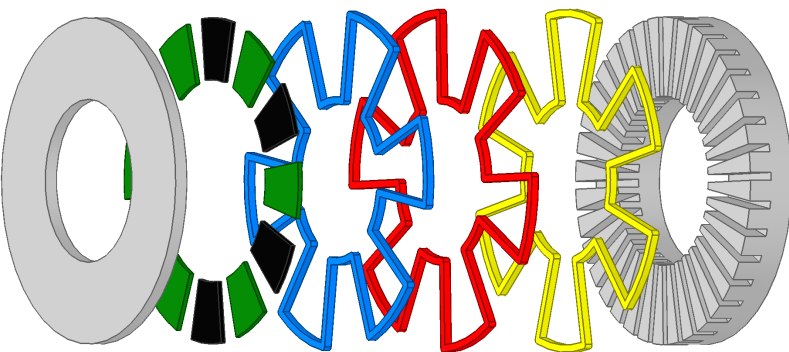

Figure 8. Exploded view for the baseline surface-mounted axial-field PM machine with 36 stator slots and 12 rotor poles. This machine employs wave type distributed windings.

Table II

SPECIFICATIONS AND CALCULATED PERFORMANCE PARAMETERS OF THE STUDIED VTFM MACHINES, ALONG WITH THOSE OF THE BASELINE AFPM MACHINE. ALL MACHINES ARE DESIGNED TO PRODUCE 56 NM AT 600 RPM, AND HAVE AN ACTIVE OUTER DIAMETER AND TOTAL AXIAL LENGTH OF 248 MM AND 52.5 MM, RESPECTIVELY.

\begin{tabular}{lrr}
\hline Machine & Baseline & VTFM 3D \\
\hline Number of stator slots & 36 & 16 \\
\hline Number of rotor poles & 12 & 56 \\
\hline Number of auxiliary stator slots & - & 2 \\
\hline Current density [A/mm2] & 7.6 & 6.9 \\
\hline Copper loss [W] & 419 & 263 \\
\hline Core loss [W] & 13 & 54 \\
\hline Total loss [W] & 432 & 317 \\
\hline Power factor & 0.78 & 0.53 \\
\hline EM efficiency [\%] & 89 & 92 \\
\hline Magnet mass [kg] & 0.365 & 0.536 \\
\hline Steel mass [kg] & 6.16 & 5.49 \\
\hline Copper mass [kg] & 2.17 & 2.17 \\
\hline Total mass [kg] & 8.7 & 8.2 \\
\hline
\end{tabular}

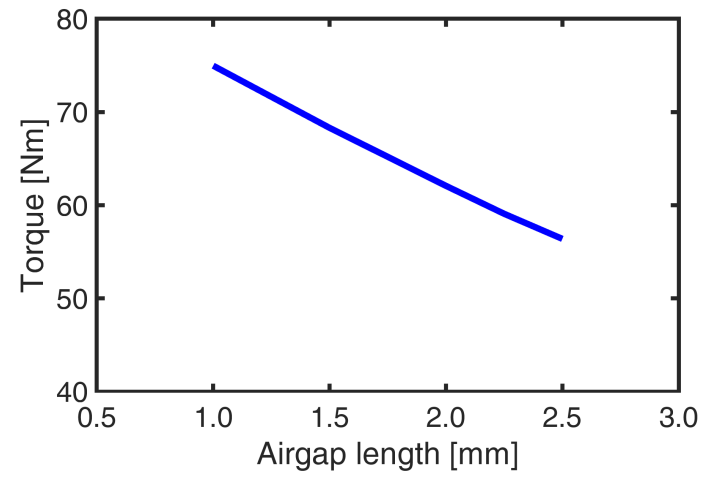

Figure 9. The variation of torque with airgap length for the baseline machine. The calculations in Table II are performed at an airgap of $2.5 \mathrm{~mm}$. 


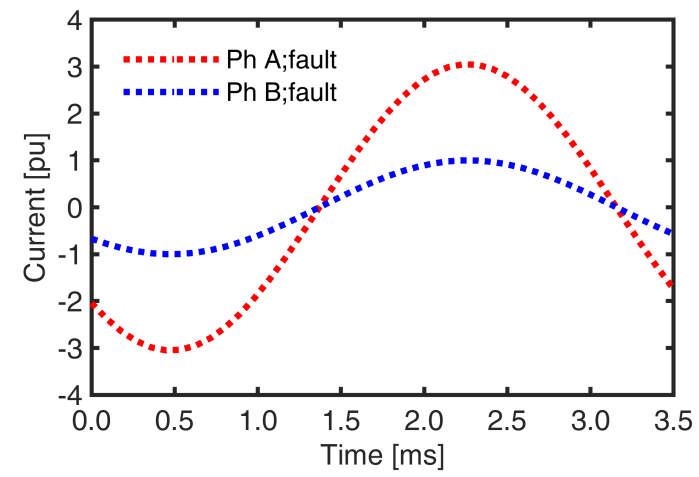

(a)

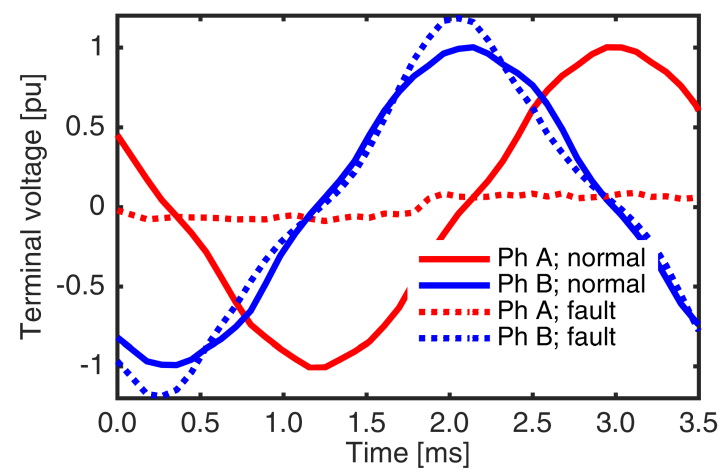

(b)

Figure 10. Demonstration of the magnetic independance of the two phases, (a) steady-state currents in p.u. during a short-circuit fault in phase A, (b) steadystate phase voltages in p.u. during the fault. Rated values are considered as the bases for the per-unitization. It is observed that the voltage in the healthy phase B shows very little change, in spite of the short-circuit fault in phase A.

computation time and transients, a short-circuit fault during normal operation is simulated on Phase A by the injection of a pure demagnetizing current, while the current in phase $\mathrm{B}$ is maintained the same (Fig. 10a), and the changes in the phase voltages are observed. It is seen that the phase A voltage reduces to nearly zero due to the fault, while the phase B voltage remains virtually unchanged from the normal operating condition (Fig. 10b). This indicates that the phases are magnetically decoupled from each other, which would reduce the risk of the fault in one phase transmitting to the other.

\section{CONCLUSION}

This paper proposes a type of two-phase axial-field VTFM machines with a single spoke rotor, and two stators. Various implementations, including those with single and dual active stators, full-pitched and concentrated windings are discussed. In contrast with conventional high-polarity PM synchronous machines, which require a large number of stator slots and coils, these machines can achieve high electrical frequency with very few stator coils and teeth, leading to simplification of the construction and manufacturing under certain conditions. An additional advantage of the two-phase construction is the inherent fault tolerance, owing to the lack of mutual coupling between the phases. Three-dimensional FEA results indicate that this machine is more suitable for use in low-speed directdrive applications. Future work will mainly include the design optimization, prototyping and testing of the proposed VTFM PM machine.

\section{ACKNOWLEDGMENT}

The support of National Science Foundation NSF Grant \#1809876, of University of Kentucky, the L. Stanley Pigman endowment and of ANSYS, Inc. is gratefully acknowledged. The authors would also like to thank Professor Ion G. Boldea from University of Politehnica of Timisoara, Timisoara, Romania, for valuable suggestions and discussions.

\section{REFERENCES}

[1] B. Mecrow and A. Jack, "A new high torque density permanent magnet machine configuration," in Proc. Int. Conf. Electr. Mach. (ICEM), Cambridge, MA, USA, 13-15 Aug. 1990.

[2] F. Zhao, T.A. Lipo and B. Kwon, "A novel dual-stator axial-flux spoketype permanent magnet vernier machine for direct-drive applications," IEEE Trans. Magn., vol. 50, no. 11, pp. 1-4, Nov. 2014.

[3] T. Zou, D. Li, R. Qu, J. Li and D. Jiang, "Analysis of a dual-rotor, toroidal-winding, axial-flux vernier permanent magnet machine," IEEE Trans. Ind. Appl., vol. 53, no. 3, pp. 1920-1930, May/Jun. 2017.

[4] I. Boldea, L. Tutelea and M. Topor, "Theoretical characterization of three phase flux reversal machine with rotor-PM flux concentration," in Proc. Int. Conf. Opt. Electr. Electron. Equip. (OPTIM), Brasov, Romania, 2426 May, 2012.

[5] Y. Liu, H. Y. Li and Z. Q. Zhu, "A High-Power Factor Vernier Machine With Coil Pitch of Two Slot Pitches," in IEEE Trans. Magn., vol. 54, no. 11, pp. 1-5, Nov. 2018.

[6] R. Zhang, J. Li, R. Qu and D. Li, "Analysis and Design of Triple-Rotor Axial-Flux Spoke-Array Vernier Permanent Magnet Machines," in IEEE Trans. Ind. Appl., vol. 54, no. 1, pp. 244-253, Jan.-Feb. 2018.

[7] V. Rallabandi, N. Taran, D. M. Ionel and I. G. Boldea, "MAGNUS-an ultra-high specific torque PM axial flux type motor with flux focusing and modulation," in Proc. IEEE Energy Convers. Congr. Expo. (ECCE), Cincinnati, OH, USA, 1-5 Oct. 2017.

[8] V. Rallabandi, N. Taran, D. M. Ionel and I. G. Boldea, "Axial-flux PM synchronous machines with air-gap profiling and very high ratio of spoke rotor poles to stator concentrated coils," in Proc. Int. Electr. Mach. Drive Conf. (IEMDC), Miami, FL, USA, 21-24 May 2017, pp. 1-7.

[9] D. Li, R. Qu and T. Lipo, "High-power-factor vernier permanent-magnet machines," IEEE Trans. Ind. Appl., vol. 50, no. 6, pp. 3664-3674, Nov./Dec. 2014.

[10] Nugen Mobility Inc., "SCM150-XXX axial flux, brushless PM motor specifications," 2007. 